\title{
Two-year controlled effectiveness trial of a school-based intervention to prevent obesity in Chilean children
}

\author{
Juliana Kain ${ }^{1, *}$, Barbara Leyton ${ }^{1}$, Ricardo Cerda ${ }^{2}$, Fernando Vio ${ }^{1}$ and Ricardo Uauy ${ }^{1,3}$ \\ ${ }^{1}$ Institute of Nutrition and Food Technology (INTA), University of Chile, Casilla 138-11, Santiago, Chile: ${ }^{2}$ School \\ of Nutrition, Faculty of Medicine, University of Chile, Santiago, Chile: ${ }^{3}$ London School of Hygiene and Tropical \\ Medicine, London, UK
}

Submitted 29 January 2008: Accepted 28 0ctober 2008: First published online 23 December 2008

\begin{abstract}
Objective: Obesity prevalence among Chilean children is $19 \cdot 4 \%$. The present study aimed to assess the effectiveness of a school-based obesity prevention programme. Design: Non-randomized controlled study. The intervention included activities in nutrition and physical activity, fully applied the first year and partially in the second one. Primary outcomes were BMI Z-score (BMIZ) and obesity prevalence; secondary outcomes were waist circumference and triceps skinfold thickness. Time effects were assessed by changes in BMI-related variables by gender and period (ANOVA and Tukey test), while intervention effects were determined by comparing changes in (i) obesity prevalence by gender and period (PROC GENMOD) and (ii) BMIZ according gender, age and period (PROC MIXED). Setting: Primary schools in the Chilean cities of Casablanca (intervention group) and Quillota (control group).

Subjects: One thousand seven hundred and fifty-nine children from three schools (intervention group) and 671 from one school (control group).

Results: Over the two years, obesity prevalence and BMIZ declined significantly in the intervention group; from $17 \cdot 0 \%$ to $12 \cdot 3 \%$ and $14 \cdot 1 \%$ to $10 \cdot 3 \%$ in boys and girls, respectively, and from 0.62 to 0.53 and 0.64 to 0.58 , respectively. In the control group, obesity remained stable at about $21 \%$ and $15 \%$, while BMIZ increased significantly in the second year. BMIZ declined in both genders and all age categories in the intervention group during the first year (significant only in younger boys). No changes occurred during the summer, while during the second year, BMIZ increased in boys and girls from both groups (significant only in the younger control boys). Obesity declined significantly only in boys during the first year.

Conclusion: Effectiveness was greater in the first school year and more evident in younger boys.
\end{abstract}

In Chile, the prevalence of obesity has risen sharply since the early $1980 \mathrm{~s}^{(1)}$ and especially in young children, whose obesity rates have increased from $7 \cdot 0 \%$ in 1987 to $18.5 \%$ in $2005^{(2)}$. This can be attributed to multiple factors linked to the nutrition transition which affect both energy intake and physical activity ${ }^{(3,4)}$. During the 1980s and 1990s, income more than doubled and poverty dropped by $50 \%$. Mean energy intake increased, especially among the urban poor. On the energy output side, sedentarism linked to urbanization increased significantly; presently, $87 \%$ of the population live in urban areas and about $90 \%$ are classified as sedentary.

The Ministry of Health acknowledged in 1997 the need to address obesity prevention by establishing a national health promotion programme (Vida Chile) with specific goals at each stage of the life course. For children, the goals are to reduce obesity at school entry (6 years of age), using WHO criteria ${ }^{(5)}$, from $16 \%$ observed in the 2000 baseline to $12 \%$ by the year 2010; and to reduce sedentary behaviour in those 15 years of age and older from $91 \%$ to $84 \%{ }^{(6)}$.

To achieve these goals, an action plan was defined focusing on schools, the workplace and community settings. Vida Chile implemented the 'Healthy School' initiative, considering that school-based programmes play an important role in promoting lifelong physical activity and healthy eating in children. However, this initiative has poorly standardized criteria for being accredited as such, and a weak evaluation component that is focused almost exclusively on process indicators. This led us in 2002 to consider the need to develop a school-based intervention to reduce overweight and obesity under controlled conditions with a strong evaluation component. It included a diet/nutrition component and enhanced physical activity, 
with an evaluation designed to assess effects on obesity prevalence and physical fitness. The initial 6-month follow-up of this programme has been described in a previous publication ${ }^{(7)}$. Results showed that BMI Z-score (BMIZ) declined significantly in boys in the intervention schools, although it remained unchanged in girls; and physical fitness parameters improved significantly in both boys and girls. Upon completion of the first year, the educational authorities of Casablanca, one of the cities that participated in the original study, requested that we consider expanding the programme to all three primary schools in the city. The present report corresponds to the continuation of the intervention for an additional two years in comparison with a concurrent non-randomized control school from a neighbouring city, Quillota, with similar socio-economic characteristics. We present here the effectiveness of the two-year intervention in terms of obesity control and anthropometric measurements.

We hypothesized that children exposed to a diet/ nutrition and physical activity intervention for two school years would show a significant difference in mean BMIZ and other anthropometric measures that would depend on the degree of implementation of the programme. We assessed the effect at the end of year one, of the summer recess and of the second school year.

\section{Methods}

\section{Participants}

Three primary schools from the city of Casablanca comprised the intervention group and one comparison school with similar socio-economic characteristics from a neighbouring city, Quillota, comprised the control group. The intervention schools represent the totality of the primary school population (1st to 8th grade) enrolled in public education in Casablanca, while the control school included all children from only one primary school. We intended to randomly select three control schools from Quillota; however, the educational authorities approved the study based on acceptance by the school principal and only one school chose to participate. We recognize this as an inherent limitation of the research, since it might introduce bias. Thus, we examined the comparability between schools of readily available factors that could affect response to an intervention: baseline BMI of children in the 1st grade and age distribution by gender. We also compared the proportion of children participating in the School Lunch Program as an indirect measure of poverty; for the control school it was $36 \%$ while the mean for the intervention schools was comparable at $32 \%$. The physical characteristics of the schools, size of the playground and the type of foods sold at kiosks were similar.

Figure 1 is a flow diagram showing the number of children assessed at each time point; losses for the 2-year study were about $15 \%$. Attrition was due mainly to children not showing up at school on the occasions when measurements were taken. Table 1 shows the distribution of the baseline sample according to group (intervention or control), age and gender. Slightly greater proportions of boys than girls were found in both groups. There were fewer children in the $>12$ years old category; this is explained by the inclusion criteria that limited entry to children starting at 7 th grade, since we required two years of follow-up. No differences were observed between the BMI of children in the intervention and control schools according to age and gender (see Table 1).

\section{Intervention programme}

The intervention was implemented as planned in 2003, while in 2004, due to funding limitations, some components were discontinued or modified. Table 2 summarizes the intervention according to school year.

In summary, the intervention changed during the second school year for reasons beyond the control of the investigators. It is evident that a weaker nutrition educational component was in place, while the physical activity component was more specifically focused to 1st and 2nd graders.

\section{Outcome measures}

The primary outcome measures were BMIZ and obesity prevalence. Secondary outcomes included waist circumference (WC), triceps skinfold thickness (TSF) and physical fitness indices. All were collected at the beginning of each school year (March or April) and repeated at the end of the school year (November). In total these measures were taken four times.

\section{Antbropometry}

Weight, height, WC and TSF were measured on all children by two trained nutritionists. Weight was taken without shoes or belts and with light clothing, and recorded to the nearest $0 \cdot 1 \mathrm{~kg}$ with a digital scale (Seca model 720); height was measured with a stadiometer to the nearest $1 \mathrm{~mm}$. BMI was calculated as weight divided by the square of height $\left(\mathrm{kg} / \mathrm{m}^{2}\right)$. Children were classified as obese if their BMI was $\geq 95$ th percentile according to the National Center for Health Statistics/Centers for Disease Control and Prevention 2000 Growth Charts ${ }^{(11)}$. This reference has been endorsed by the Chilean Ministry of Health $^{(12)}$. WC was measured standing with a non-elastic tape which was applied horizontally midway between the lowest rib margin and the iliac crest. TSF was determined with Lange callipers to the nearest $1 \mathrm{~mm}$ based on the average of three consecutive measurements taken at the mid-point of the left arm hanging straight.

To assess physical fitness, the following measures were taken: for children in the 1 st to 4 th grades, broad jump, a modified shuttle run test and the mile test; while for children in the 5 th grade and above we assessed the $20 \mathrm{~m}$ shuttle run test ${ }^{(13)}$. These will be reported separately. 


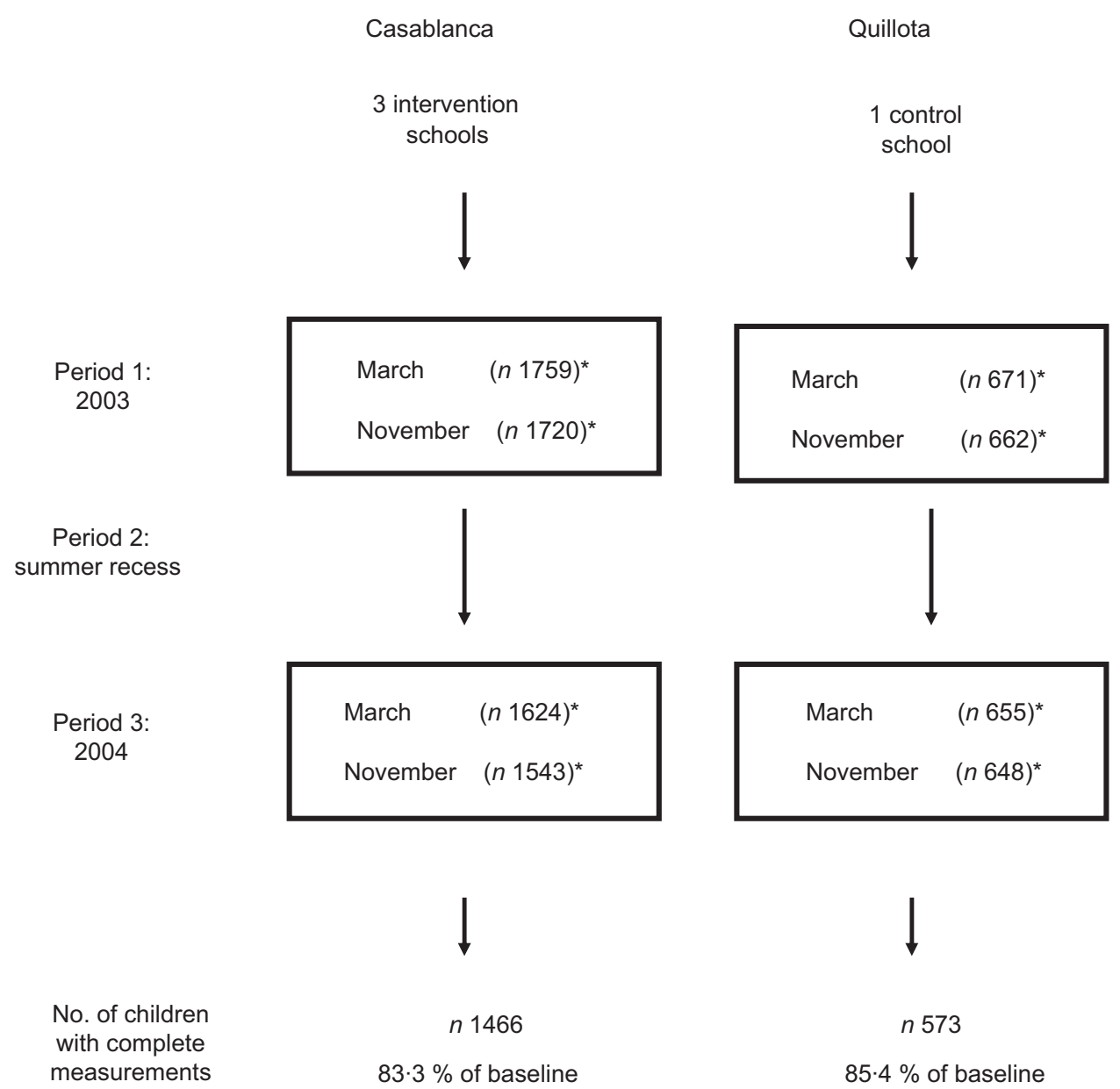

Fig. 1 Flow diagram showing the number of children assessed at each time point in a 2-year controlled effectiveness trial of a school-based intervention to prevent obesity in Chilean children. ${ }^{*}$ Weight, height, waist circumference and triceps skinfold thickness were collected

Table 1 Anthropometric characteristics of the baseline sample of children from the intervention (I) and control (C) schools by age and gender: 2-year controlled effectiveness trial of a school-based intervention to prevent obesity in Chilean children

\begin{tabular}{|c|c|c|c|c|c|c|c|c|c|c|c|c|c|c|}
\hline & & & \multicolumn{4}{|c|}{ Weight (kg) } & \multicolumn{4}{|c|}{ Height (cm) } & \multicolumn{4}{|c|}{ BMI $\left(\mathrm{kg} / \mathrm{m}^{2}\right)$} \\
\hline & \multicolumn{2}{|c|}{$n$} & \multicolumn{2}{|c|}{ I } & \multicolumn{2}{|c|}{$\mathrm{C}$} & \multicolumn{2}{|c|}{ I } & \multicolumn{2}{|c|}{$\mathrm{C}$} & \multicolumn{2}{|c|}{ I } & \multicolumn{2}{|c|}{$\mathrm{C}$} \\
\hline & I & C & Mean & SD & Mean & SD & Mean & SD & Mean & SD & Mean & SD & Mean & SD \\
\hline \multicolumn{15}{|l|}{ Boys } \\
\hline$<8$ years & 153 & 76 & $26 \cdot 0$ & $5 \cdot 8$ & $25 \cdot 4$ & $5 \cdot 6$ & $120 \cdot 8$ & $6 \cdot 2$ & $120 \cdot 0$ & $5 \cdot 6$ & $17 \cdot 7$ & $2 \cdot 6$ & $17 \cdot 6$ & $2 \cdot 8$ \\
\hline $8-10$ years & 215 & 101 & $32 \cdot 2$ & $6 \cdot 7$ & $33 \cdot 0$ & $7 \cdot 1$ & $131 \cdot 5$ & $5 \cdot 9$ & $131 \cdot 4$ & $6 \cdot 5$ & $18 \cdot 5$ & $2 \cdot 9$ & $18 \cdot 9$ & $2 \cdot 9$ \\
\hline $10-12$ years & 213 & 108 & $38 \cdot 8$ & $9 \cdot 3$ & $41 \cdot 5$ & $10 \cdot 4$ & $141 \cdot 2$ & $7 \cdot 3$ & $141 \cdot 9$ & $6 \cdot 8$ & $19 \cdot 3$ & $3 \cdot 3$ & $20 \cdot 4$ & $3 \cdot 9$ \\
\hline$>12$ years & 168 & 63 & $48 \cdot 4$ & $11 \cdot 6$ & $47 \cdot 4$ & $12 \cdot 8$ & $152 \cdot 6$ & $8 \cdot 5$ & $150 \cdot 9$ & $8 \cdot 5$ & $20 \cdot 6$ & $3 \cdot 7$ & $20 \cdot 5$ & $4 \cdot 1$ \\
\hline Total & 749 & 348 & $36 \cdot 5$ & $11 \cdot 6$ & $36 \cdot 7$ & $12 \cdot 1$ & $136 \cdot 8$ & $13 \cdot 1$ & $136 \cdot 0$ & $12 \cdot 6$ & $19 \cdot 0$ & $3 \cdot 3$ & $19 \cdot 4$ & $3 \cdot 7$ \\
\hline \multicolumn{15}{|l|}{ Girls } \\
\hline$<8$ years & 179 & 55 & $25 \cdot 1$ & $5 \cdot 5$ & $24 \cdot 3$ & $4 \cdot 2$ & $119 \cdot 7$ & $6 \cdot 4$ & $118 \cdot 3$ & $5 \cdot 9$ & $17 \cdot 3$ & $2 \cdot 6$ & $17 \cdot 3$ & $2 \cdot 3$ \\
\hline $8-10$ years & 201 & 50 & $33 \cdot 3$ & $8 \cdot 1$ & $31 \cdot 1$ & $7 \cdot 1$ & $132 \cdot 1$ & $7 \cdot 0$ & $130 \cdot 3$ & $7 \cdot 5$ & $18 \cdot 9$ & $3 \cdot 3$ & $18 \cdot 2$ & $2 \cdot 8$ \\
\hline $10-12$ years & 195 & 74 & $41 \cdot 4$ & $9 \cdot 6$ & $41 \cdot 4$ & $9 \cdot 3$ & $143 \cdot 8$ & $7 \cdot 5$ & $142 \cdot 6$ & $7 \cdot 0$ & $19 \cdot 8$ & $3 \cdot 5$ & $20 \cdot 2$ & $3 \cdot 6$ \\
\hline$>12$ years & 142 & 46 & $49 \cdot 5$ & $11 \cdot 8$ & $51 \cdot 4$ & $13 \cdot 1$ & $151 \cdot 9$ & $7 \cdot 1$ & $152 \cdot 4$ & $6 \cdot 5$ & $21 \cdot 3$ & $4 \cdot 1$ & $22 \cdot 0$ & $5 \cdot 2$ \\
\hline Total & 717 & 225 & $36 \cdot 6$ & $12 \cdot 2$ & $37 \cdot 0$ & $13 \cdot 2$ & $135 \cdot 9$ & $13 \cdot 6$ & $135 \cdot 9$ & $14 \cdot 1$ & $19 \cdot 3$ & 3.5 & $19 \cdot 4$ & $4 \cdot 0$ \\
\hline
\end{tabular}

\section{Data analysis}

We assessed post hoc power and significance that resulted from a total sample size of 2000 subjects. The power estimation considered that, over the two years, BMIZ would increase by $0 \cdot 1$ units in the control school while remaining unchanged in the intervention schools (significance $=0 \cdot 05$, power $=0 \cdot 89$ ).

The difference in mean BMIZ at baseline comparing children in the intervention schools who completed the study with those lost to follow-up was $+0 \cdot 14(P=0 \cdot 009)$, 
Table 2 Diet and nutrition and physical activity components of the intervention by school year: 2-year controlled effectiveness trial of a school-based intervention to prevent obesity in Chilean children

\begin{tabular}{|c|c|c|}
\hline Year & Diet and nutrition & Physical activity \\
\hline 2003 & $\begin{array}{l}\text { Teachers (4th-7th grades): } \\
\text { training by nutritionist, } 10 \mathrm{~h} \text { in total } \\
\text { Children: } \\
\text { contents on healthy eating from trained teachers }{ }^{(8,9)} \\
\text { 4th-6th grades: } 8-11 \mathrm{~h} \\
\text { 7th grade: } 5-6 \mathrm{~h} \\
\text { Parental involvement: } \\
\text { two educational lessons by the nutritionist to parents } \\
\text { of } 4 \text { th-7th grade children } \\
\text { Supervised by nutritionist }\end{array}$ & $\begin{array}{l}\text { Teachers (4th-7th grades): } \\
\text { trained in the CALC program }{ }^{(10)} \\
\text { Children: } \\
90 \text { min of additional weekly PE classes } \\
\text { four sessions to } 1 \text { st-4th grade teachers }(n 28) \text { on correct } \\
\text { application of PE curriculum } \\
\text { active recess during } 4 \text { months } \\
\text { Supervised by PE teacher }\end{array}$ \\
\hline 2004 & $\begin{array}{l}\text { Teachers: } \\
\text { no training } \\
\text { Children: } \\
\text { contents on healthy eating from teachers } \\
\text { 5th-8th grades: } 4 \mathrm{~h} \text { in total } \\
\text { Parental involvement: } \\
\text { no systematic educational efforts; one group meeting by } \\
\text { nutritionist from health department advising parents of } \\
\text { obese children } \\
\text { No supervision }\end{array}$ & $\begin{array}{l}\text { Teachers: } \\
\text { CALC program discontinued, replaced by training of } 9 \\
\text { (out of 28) teachers to improve quality of PE classes } \\
\text { Children: } \\
\quad 90 \text { min of additional weekly PE classes } \\
\text { active recess discontinued } \\
\text { No supervision }\end{array}$ \\
\hline
\end{tabular}

$\mathrm{PE}$, physical education.

while in the control school the difference was $+0 \cdot 02$ (NS). The comparability of the outcome variables at baseline by gender was determined using ANOVA, except for obesity prevalence.

We also compared these variables for intervention and control groups by gender, between baseline and the end of the study period, using repeated-measures ANOVA (adjusting for baseline values) and the Tukey test to assess whether the differences were significant $(P<0 \cdot 05)$. We determined if there was a statistical difference between change in obesity prevalence between groups in period 1 and in period 3, and over the two years by gender, using PROC GENMOD (SAS) for categorical variables, adjusting for baseline values ${ }^{(14)}$.

To assess the effectiveness of the intervention according to the mode delivered, we divided the 21 months observation time (March 2003 to November 2004) into three different periods: (i) period 1, first school year (full intervention), lasting from March to November 2003; (ii) period 2, December 2003 to March 2004, summer recess (children received no intervention); and (iii) period 3 or the second school year (partial intervention, March to November 2004).

The effect of the programme on BMIZ was analysed by comparing the changes according to period of study, gender and age category $(<8,8-10,10-12$ and $>12$ years). Since our assessment is standardized by age, we chose age rather than grades; both are closely related.

We also determined the changes in the secondary outcomes (WC and TSF) in the study group by comparing follow-up with baseline values. The data were standardized by gender and age and expressed as $Z$-score changes relative to the reference from the Third National
Health and Nutrition Examination Survey (NHANES III) for WC and TSF specific for age and gender ${ }^{(15)}$. These values were then log transformed to meet normality for statistical analysis.

All analyses were performed using a mixed model of covariance (SAS, PROC MIXED), assessing each of three independent variables (group, age and period) and their interaction for each gender, adjusting for baseline value. Groups were separated by age category only if the interaction term was significant, defined by $P<0 \cdot 05$. In addition, the Tukey test adjusting the $P$ value for multiple comparisons was used for post hoc contrast of age, gender and period by intervention group; adjusted $P<0.05$ was considered significant. These comparisons included intervention $v$. control in each period of the study and intervention period $1 v$. period 2 and period 3 separately. These same comparisons were assessed in the control group. All statistical analyses were performed using the SAS statistical software package version $8 \cdot 2$ (SAS Institute Inc., Cary, NC, USA).

\section{Results}

\section{Comparability of subjects at baseline}

Table 1 shows the baseline data for weight, height and BMI for children in the intervention and control schools, according to age category and gender. The proportion of children by age category was similar, although the gender distribution was different across ages. Overall, there were $51 \cdot 1 \%$ and $60 \cdot 7 \%$ boys in the intervention and control schools, respectively. BMI was similar in all age categories for children from intervention and control schools by 
Table 3 Changes in anthropometric characteristics and obesity prevalence in intervention and control boys over the two years: 2-year controlled effectiveness trial of a school-based intervention to prevent obesity in Chilean children

\begin{tabular}{|c|c|c|c|c|c|c|c|c|c|c|c|c|c|c|c|c|}
\hline & \multicolumn{8}{|c|}{ Intervention group } & \multicolumn{8}{|c|}{ Control group } \\
\hline & \multicolumn{8}{|c|}{ Period 2} & \multicolumn{8}{|c|}{ Period 2} \\
\hline & \multicolumn{4}{|c|}{ Period 1} & \multicolumn{4}{|c|}{ Period 3} & \multicolumn{4}{|c|}{ Period 1} & \multicolumn{4}{|c|}{ Period 3} \\
\hline & \multicolumn{2}{|c|}{ Mar 03} & \multicolumn{2}{|c|}{ Nov 03} & \multicolumn{2}{|c|}{ Mar 04} & \multicolumn{2}{|c|}{ Nov 04} & \multicolumn{2}{|c|}{ Mar 03} & \multicolumn{2}{|c|}{ Nov 03} & \multicolumn{2}{|c|}{ Mar 04} & \multicolumn{2}{|c|}{ Nov 04} \\
\hline & Mean & SD & Mean & SD & Mean & SD & Mean & SD & Mean & SD & Mean & SD & Mean & SD & Mean & SD \\
\hline Age (years) & $10 \cdot 0$ & $2 \cdot 3$ & $10 \cdot 6$ & $2 \cdot 2$ & $11 \cdot 2$ & $2 \cdot 3$ & $11 \cdot 6$ & $2 \cdot 2$ & $9 \cdot 9$ & $2 \cdot 1$ & $10 \cdot 5$ & $2 \cdot 1$ & $11 \cdot 1$ & $2 \cdot 1$ & $11 \cdot 5$ & $2 \cdot 1$ \\
\hline BMI $\left(\mathrm{kg} / \mathrm{m}^{2}\right)$ & $19 \cdot 0$ & $3 \cdot 3$ & $18 \cdot 8$ & $3 \cdot 2$ & $19 \cdot 1$ & $3 \cdot 2$ & $19 \cdot 7$ & $3 \cdot 2$ & $19 \cdot 4$ & $3 \cdot 8$ & $19 \cdot 5$ & $3 \cdot 7$ & $20 \cdot 0$ & $3 \cdot 7$ & $20 \cdot 6$ & $3 \cdot 7$ \\
\hline BMIZ & 0.62 & $1 \cdot 00$ & $0.44^{\mathrm{a}}$ & $1 \cdot 00$ & $0.42^{b}$ & $1 \cdot 00$ & $0.53^{\mathrm{c}}$ & 0.95 & 0.67 & $1 \cdot 00$ & $0 \cdot 65^{\mathrm{a}}$ & $1 \cdot 00$ & $0 \cdot 65^{\mathrm{b}}$ & $1 \cdot 00$ & $0.72^{c}$ & $1 \cdot 00$ \\
\hline WC (cm) & $64 \cdot 9$ & $9 \cdot 7$ & $65 \cdot 5$ & $9 \cdot 4$ & $66 \cdot 4^{\mathrm{b}}$ & $9 \cdot 0$ & $68 \cdot 0^{\mathrm{C}}$ & $8 \cdot 8$ & $65 \cdot 6$ & $10 \cdot 6$ & $67 \cdot 0^{\mathrm{a}}$ & $10 \cdot 5$ & $67 \cdot 0^{\mathrm{b}}$ & $10 \cdot 1$ & $68 \cdot 5^{\mathrm{c}}$ & $9 \cdot 4$ \\
\hline $\operatorname{TSF}(\mathrm{mm})$ & $12 \cdot 2$ & $5 \cdot 8$ & $12 \cdot 8^{\mathrm{a}}$ & $5 \cdot 5$ & $13 \cdot 1^{\mathrm{b}}$ & $5 \cdot 8$ & $14 \cdot 2^{\mathrm{C}}$ & $6 \cdot 3$ & $13 \cdot 0$ & $6 \cdot 3$ & $14 \cdot 2^{\mathrm{a}}$ & $6 \cdot 5$ & $14 \cdot 3^{\mathrm{b}}$ & 6.9 & $15 \cdot 6^{\mathrm{c}}$ & $6 \cdot 8$ \\
\hline$\%$ Obese & \multicolumn{2}{|c|}{$17 \cdot 0$} & \multicolumn{2}{|c|}{$11 \cdot 4^{\mathrm{d}}$} & \multicolumn{2}{|c|}{$11 \cdot 4$} & \multicolumn{2}{|c|}{$12 \cdot 3^{\mathrm{e}}$} & \multicolumn{2}{|c|}{$21 \cdot 6$} & \multicolumn{2}{|c|}{$19 \cdot 7$} & \multicolumn{2}{|c|}{$19 \cdot 4$} & \multicolumn{2}{|c|}{$21 \cdot 4$} \\
\hline
\end{tabular}

BMIZ, BMI Z-score; WC, waist circumference; TSF, triceps skinfold thickness.

Time effects were assessed using repeated-measures ANOVA (adjusted for baseline values) and the Tukey test for significance $(P<0.05)$ : ${ }^{\circ}$ significant difference between Mar 03 and Nov 03; ${ }^{b}$ significant difference between Mar 03 and Mar $04 ;{ }^{c}$ significant difference between Mar 03 and Nov 04.

Intervention effects were assessed using PROC GENMOD (SAS) adjusted for baseline values: ${ }^{d}$ significant difference in change in obesity prevalence between intervention and control groups in Period 1 ; ${ }^{\mathrm{e}}$ significant difference in changes in obesity prevalence between intervention and control groups over the two years.

gender. Tables 3 and 4 present the outcome variables for boys and girls, respectively, in both groups by study period. In boys, the prevalence of obesity at baseline was significantly higher in the control group $(21 \cdot 6 \% v \cdot 17 \cdot 0 \%$ in the intervention group); in girls these were similar. The comparison between baseline BMIZ in both groups showed that there was no significant overall difference in either boys or girls ( $P=0.99$ and $1 \cdot 0$, respectively), although a difference was found in boys of one age category (10-12 years). Considering this as a potential confounder, all analyses were adjusted by baseline BMIZ in assessing the effectiveness of the intervention.

The secondary outcome variables (WC and TSF) were similar for both genders and in all age groupings at baseline.

\section{Effect of the intervention on antbropometry}

The changes over time in BMI-related indices in the intervention and control groups are shown in Tables 3 and 4 . In boys (Table 3), mean BMI in the intervention schools declined during the first period and increased slightly thereafter. Baseline BMI for boys in the control school remained unchanged during the first study period; it increased over time by 0.31 units over the expected for the median during the 21-month observation period. This is better reflected by examining the BMIZ; a significant decrease occurred in the intervention schools during the first period (from 0.62 to 0.44 ), while in the third period it increased by $0 \cdot 12$. In the control school, BMIZ remained virtually unchanged during the first two periods, but increased significantly during the third one. The possibility that this effect could be partly explained by differential attrition rates in the intervention schools, promoting the loss of those with higher BMIZ, appears unlikely, since at baseline the difference in BMIZ for those lost to follow-up was $-0 \cdot 14$.
Mean WC for boys from both groups increased similarly over time. Mean TSF for boys from the intervention and control schools was $12 \cdot 2$ and $13 \cdot 0 \mathrm{~mm}$, respectively, at baseline; these rose accordingly, but the increase was greater in the control group. The values at follow-up were $14 \cdot 2$ and $15.6 \mathrm{~mm}$ for the intervention and control groups, respectively.

The comparative analysis among anthropometric variables at the end of each period relative to baseline for both the intervention and the control groups for boys indicated that there was a significant decline in BMIZ in periods 1 and 2 in both groups, although the decline was much greater in the intervention group. At the end of period 3, relative to baseline, these values were significantly lower in the intervention group and significantly higher in the control group. The comparative analysis for WC showed that the values in both groups were significantly higher in each period relative to baseline, except in period 2 in the intervention group. For TSF, significant differences were observed the end of each study period relative to baseline for both groups.

In girls (Table 4), mean BMI in both the intervention and control schools remained stable during the first two periods and increased slightly thereafter. BMIZ in the intervention schools declined from 0.64 to 0.52 , remained unchanged and increased to 0.60 in the last period; in control girls, there was also an initial decline, although smaller, and a greater increase during the last period. Mean WC values over time for girls from both groups were very similar, increasing progressively as expected, from about 65 to $68 \mathrm{~cm}$. The trend for mean TSF showed a similar increase in both groups, although the rise during the third period was considerably greater in the control girls.

The comparative analysis of anthropometric variables at the end of each period relative to baseline for girls showed that BMIZ values were all significantly lower in 
Table 4 Changes in anthropometric characteristics and obesity prevalence in intervention and control girls over the two years: 2-year controlled effectiveness trial of a school-based intervention to prevent obesity in Chilean children

\begin{tabular}{|c|c|c|c|c|c|c|c|c|c|c|c|c|c|c|c|c|}
\hline & \multicolumn{8}{|c|}{ Intervention group } & \multicolumn{8}{|c|}{ Control group } \\
\hline & \multicolumn{8}{|c|}{ Period 2} & \multicolumn{8}{|c|}{ Period 2} \\
\hline & \multicolumn{4}{|c|}{ Period 1} & \multicolumn{4}{|c|}{ Period 3} & \multicolumn{4}{|c|}{ Period 1} & \multicolumn{4}{|c|}{ Period 3} \\
\hline & \multicolumn{2}{|c|}{ Mar 03} & \multicolumn{2}{|c|}{ Nov 03} & \multicolumn{2}{|c|}{ Mar 04} & \multicolumn{2}{|c|}{ Nov 04} & \multicolumn{2}{|c|}{ Mar 03} & \multicolumn{2}{|c|}{ Nov 03} & \multicolumn{2}{|c|}{ Mar 04} & \multicolumn{2}{|c|}{ Nov 04} \\
\hline & Mean & SD & Mean & SD & Mean & SD & Mean & SD & Mean & SD & Mean & SD & Mean & SD & Mean & SD \\
\hline Age (years) & $9 \cdot 8$ & $2 \cdot 3$ & $10 \cdot 4$ & $2 \cdot 3$ & $11 \cdot 0$ & $2 \cdot 3$ & $11 \cdot 4$ & $2 \cdot 3$ & $9 \cdot 9$ & $2 \cdot 2$ & $10 \cdot 5$ & $2 \cdot 2$ & $11 \cdot 2$ & $2 \cdot 2$ & $11 \cdot 5$ & $2 \cdot 2$ \\
\hline BMl $\left(\mathrm{kg} / \mathrm{m}^{2}\right)$ & $19 \cdot 3$ & $3 \cdot 5$ & $19 \cdot 2$ & $3 \cdot 4$ & $19 \cdot 6$ & $3 \cdot 5$ & $20 \cdot 1$ & 3.5 & $19 \cdot 4$ & $4 \cdot 0$ & $19 \cdot 6$ & $4 \cdot 0$ & $20 \cdot 0$ & $4 \cdot 0$ & $20 \cdot 8$ & $3 \cdot 8$ \\
\hline BMIZ & 0.64 & 0.95 & $0 \cdot 51^{a}$ & 0.92 & $0.50^{\mathrm{b}}$ & 0.93 & $0.58^{\mathrm{C}}$ & 0.90 & 0.64 & 1.00 & 0.59 & 1.00 & $0.57^{b}$ & 0.90 & $0.72^{c}$ & 0.90 \\
\hline WC (cm) & $64 \cdot 9$ & $9 \cdot 9$ & $65 \cdot 5^{\mathrm{a}}$ & $9 \cdot 5$ & $65 \cdot 8^{\mathrm{b}}$ & $9 \cdot 4$ & $67 \cdot 7^{\mathrm{C}}$ & $9 \cdot 1$ & $64 \cdot 0$ & $10 \cdot 2$ & $66 \cdot 0^{\mathrm{a}}$ & $10 \cdot 0$ & $65 \cdot 7^{\mathrm{b}}$ & $9 \cdot 5$ & $67 \cdot 3^{c}$ & $9 \cdot 1$ \\
\hline TSF (mm) & $14 \cdot 8$ & $5 \cdot 9$ & $15 \cdot 4^{\mathrm{a}}$ & $5 \cdot 5$ & $16 \cdot 0^{\mathrm{b}}$ & $5 \cdot 7$ & $17 \cdot 5^{\mathrm{c}}$ & $6 \cdot 1$ & $14 \cdot 7$ & $5 \cdot 7$ & $15 \cdot 9^{a}$ & $5 \cdot 8$ & $16 \cdot 6^{\mathrm{b}}$ & $5 \cdot 7$ & $18 \cdot 9^{\mathrm{C}}$ & $6 \cdot 3$ \\
\hline$\%$ Obese & \multicolumn{2}{|c|}{$14 \cdot 1$} & \multicolumn{2}{|c|}{$10 \cdot 3$} & \multicolumn{2}{|c|}{$9 \cdot 9$} & \multicolumn{2}{|c|}{$10 \cdot 3^{d}$} & \multicolumn{2}{|c|}{$14 \cdot 7$} & \multicolumn{2}{|c|}{$12 \cdot 6$} & \multicolumn{2}{|c|}{$11 \cdot 8$} & \multicolumn{2}{|c|}{$15 \cdot 2$} \\
\hline
\end{tabular}

BMIZ, BMI Z-score; WC, waist circumference; TSF, triceps skinfold thickness.

Time effects were assessed using repeated-measures ANOVA (adjusted for baseline values) and the Tukey test for significance $(P<0 \cdot 05)$ : ${ }^{a}$ significant difference between Mar 03 and Nov 03; ${ }^{b}$ significant difference between Mar 03 and Mar 04; ${ }^{c}$ significant difference between Mar 03 and Nov 04.

Intervention effects were assessed using PROC GENMOD (SAS) adjusted for baseline values: ${ }^{d}$ significant difference in changes in obesity prevalence between intervention and control groups over the two years.

intervention girls, while in control girls, it was lower only at the end of period 2. At the end of period 3, BMIZ was significantly higher in the control school. Mean change in WC and TSF showed that these were significantly higher in each period relative to baseline in both groups, although for TSF, the value at the end of period 3 was much higher in the control group.

Obesity prevalence in boys declined significantly in the intervention group during the first period compared with the change observed in the control group $(17 \cdot 0 \%$ to $11 \cdot 4 \%$ v. $21 \cdot 6 \%$ to $19 \cdot 7 \%$ ). In girls, the decline in obesity prevalence during period 1 was similar between groups. Changes during period 3 for both genders were similar between groups. When comparing the obesity prevalence between the end of the study period and baseline, the decline was significant for both genders.

\section{Effect of the intervention on changes in anthropometry over the study periods}

We tested the effectiveness of the intervention by comparing the changes in BMIZ during each period by group, gender and age, using PROC MIXED. For boys, the group $\times$ period $\times$ age interaction was significant $(P=0 \cdot 031)$, while for girls it was of borderline significance $(P=0 \cdot 051)$. Thus, we compared the changes in BMIZ from intervention and control schools according to study period and age category at entry, adjusting by baseline BMIZ.

Comparison between the intervention and control groups in each period (Fig. 2 for boys and Fig. 3 for girls) showed a decline in BMIZ of boys from intervention schools in all age categories in period 1, this was statistically significant only in the youngest category; while in controls no differences were noted. During the summer recess (period 2), practically no changes were observed in either group. During period 3, BMIZ increased in both groups across all age categories; however, the rise was significantly greater for controls in the youngest category. For girls, a non-significant decline in BMIZ for intervention schools in all age categories was noted in period 1. During the summer recess (period 2), practically no changes were observed in both groups. In period 3, BMIZ increased non-significantly in both groups across all age categories.

Comparison of periods 2 and 3 relative to period 1 (Figs 2 and 3) showed that the changes in BMIZ for boys in the intervention schools between periods 1 and 2 were significantly different for all age groups except the oldest, reflecting the fact that during the summer recess no intervention was in place. For controls, no significant changes were noted. For girls, changes were of lower magnitude and significant only in the intervention group in two age categories. For control girls, no significant changes were noted. BMIZ changes between periods 1 and 3 for boys and girls in the intervention group were significant across all age groups. In the case of controls, significant changes between periods 1 and 3 were also noted in boys and girls for all age groups except the oldest. This suggests that there was a likely concurrent phenomenon that affected both intervention and control groups similarly during the second school year or that the effect of intervention was not demonstrable.

Similar evaluation for secondary outcomes (WC and TSF; data not shown) revealed no significant changes between intervention and control groups across all periods, age categories and gender. The exception was a significantly lower rise in WC in the youngest group during period 1 for boys and girls; this is consistent with the observed effect in BMIZ. In terms of the comparison of WC changes between periods 2 and 3 relative to 1 , a significant rise was observed in the intervention group between period 3 and period 1 in both genders as was a significant drop in WC in girls from the control group 

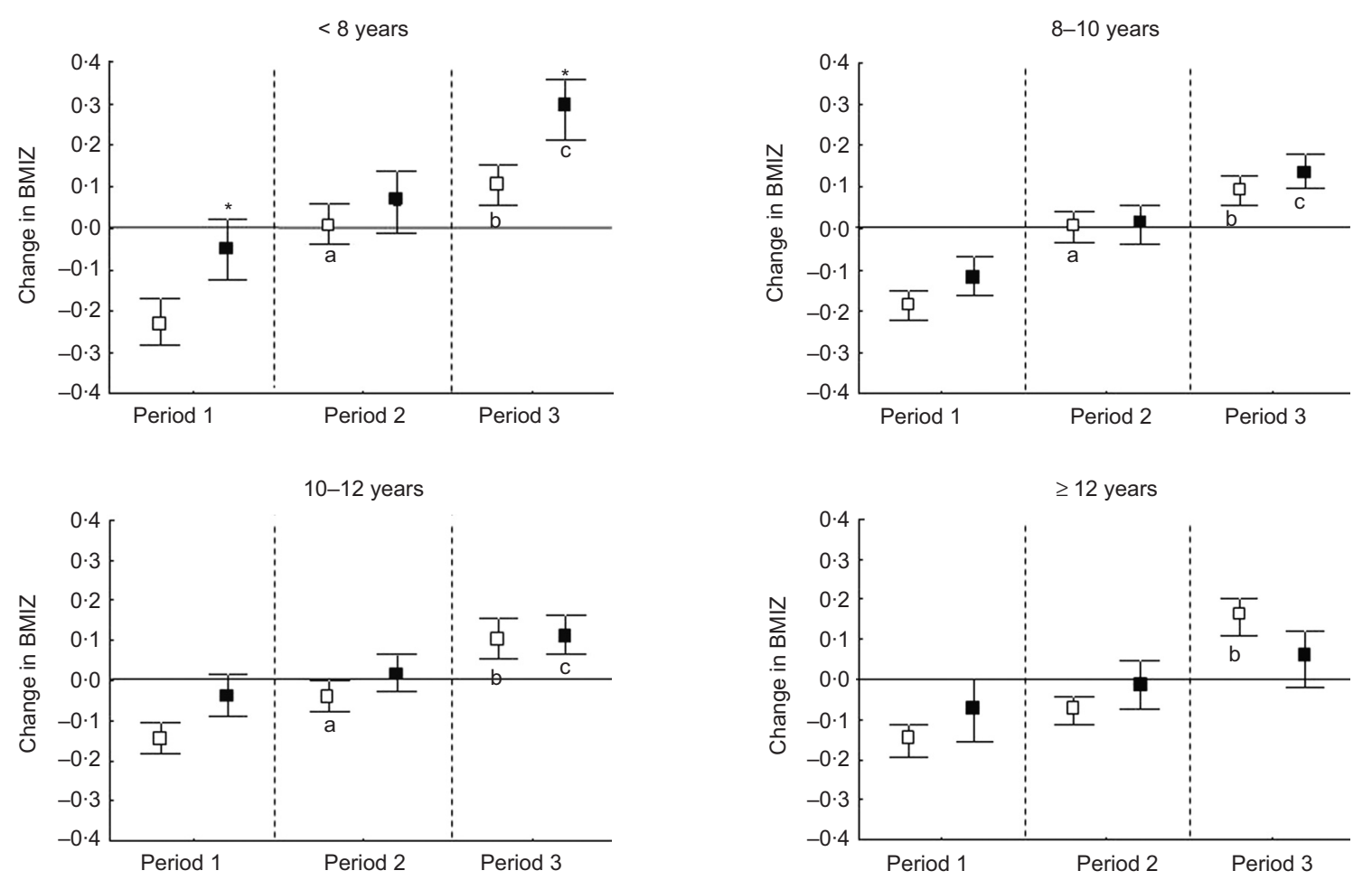

Fig. 2 Change in mean BMI Z-score (BMIZ) in boys $(95 \% \mathrm{Cl})$ relative to baseline, in intervention ( $\square)$ and control schools ( $\mathbf{\square})$ according to age and period of study (Period 1, Mar 03-Nov 03; Period 2, Nov 03-Mar 04; Period 3, Mar 04-Nov 04). PROC MIXED and the Tukey test were used to compare intervention $v$. control groups and time effects. Significant change over baseline $(P<0.05)$ is defined by $\mathrm{Cl}$ range excluding 0 . Significant difference between intervention and control $(P<0.05)$ is marked by *.

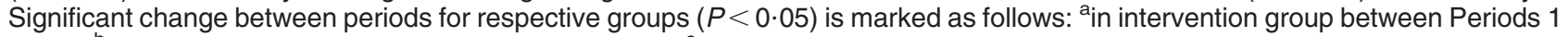
and 2; ${ }^{b}$ in intervention group between Periods 1 and 3 ; ${ }^{\text {in }}$ control group between Periods 1 and 3

between period 2 and period 1. The same analysis for TSF revealed that only in the older group was there a significant rise in boys and girls from the intervention group in period 3 relative to period 1 .

\section{Discussion}

The main findings of the present study are the significant decline in BMIZ in both boys and girls from the intervention schools compared with the rise in controls and the smaller increase in TSF in the intervention schools relative to controls for both boys and girls. There was a greater effect in terms of BMI changes in younger age groups, while the impact was minimal in children over 12 years of age. The effects were noted mainly during the first year of the intervention when it was applied as planned; during the summer recess, values remained unchanged; and in the second year when the intervention was weaker, values regressed, although less so in the intervention group compared with controls. Effectiveness was significant as measured by the main outcomes in the younger boys during period 1 , although in period 3 there was a beneficial effect in terms of ameliorating the rise in BMIZ observed in the second year for both groups. The possible effect of differential attrition rates according to baseline BMI, i.e. greater loss of obese children in the intervention schools, was tested and in fact those lost to follow-up were found to be leaner at baseline; supporting a true effect of the intervention. In contrast, in the control group those lost to follow-up were similar at baseline.

Obesity prevalence decreased significantly in the intervention group during the first school year only in boys. Changes in obesity prevalence were more marked than those observed in BMIZ; this is expected since there is a potential greater effect in the size of the upper tail of the distribution which includes the obese population. The stable values observed during the recess period serve to illustrate that there was no carry-over when the school year ended; moreover, there were no differences between the two groups for that period.

During the second year the intervention could not be maintained in its integrity due to limitations in funding. Thus, we are not able ascertain if differences in impact during this period were due to the weaker nutrition education component or the discontinuation of the CALC program, as other activities were maintained. In fact, judged on the basis of the observed effects on BMIZ, WC and TSF, there was some indication of a reversal of the gain achieved the previous year, although the rise in BMIZ was significantly greater in controls relative to the 
$<8$ years

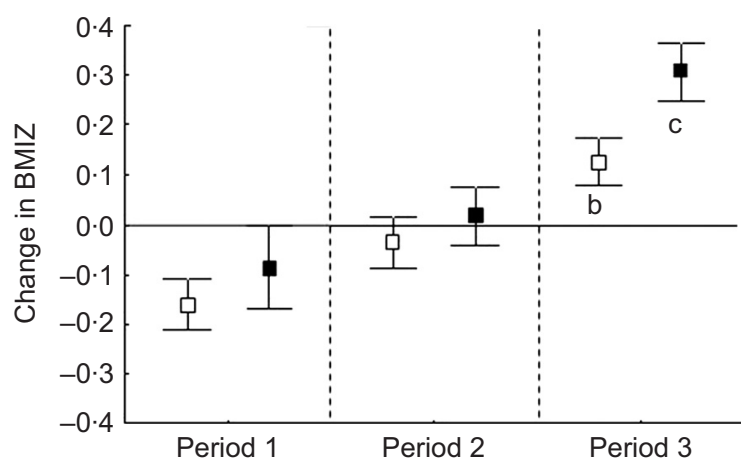

10-12 years

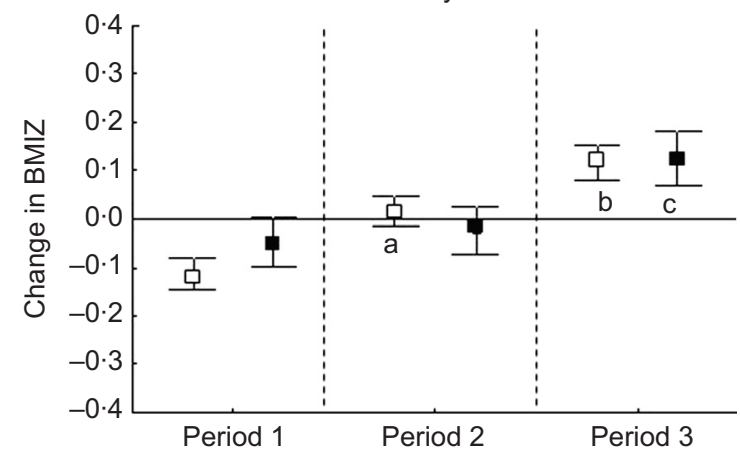

8-10 years

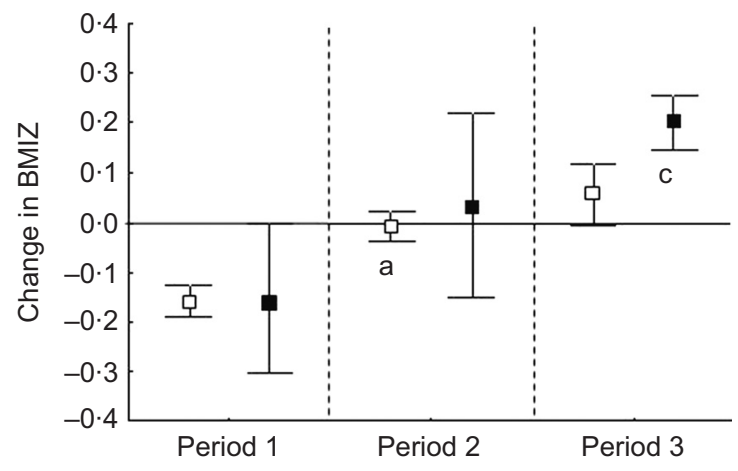

$\geq 12$ years

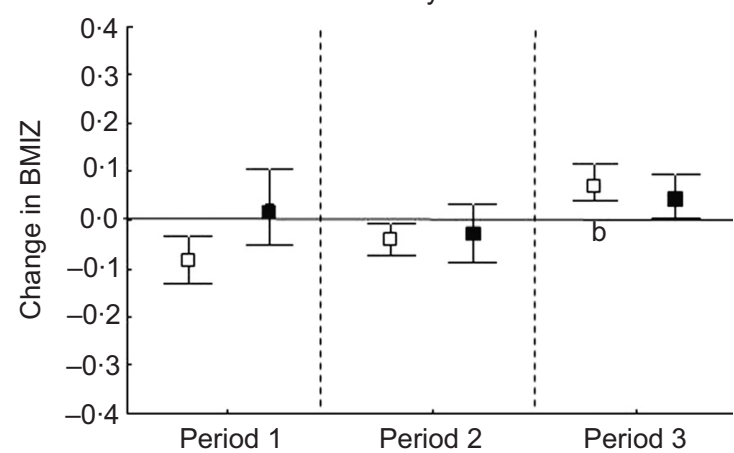

Fig. 3 Change in mean BMI Z-score (BMIZ) in girls (95\% Cl) relative to baseline, in intervention ( $\square)$ and control schools $(\square)$ according to age and period of study (Period 1, Mar 03-Nov 03; Period 2, Nov 03-Mar 04; Period 3, Mar 04-Nov 04). PROC MIXED and the Tukey test were used to compare intervention $v$. control groups and time effects. Significant change over baseline $(P<0.05)$ is defined by $\mathrm{Cl}$ range excluding 0 . Significant change between periods for respective groups $(P<0.05)$ is marked as

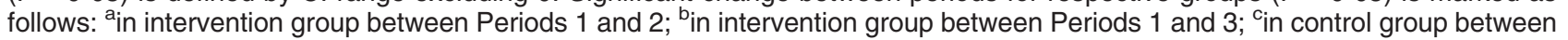
Periods 1 and 3

intervention children. This suggests that, despite no observed further decline, the intervention may have been protective against factors which induced the rise in BMIZ in controls. We are uncertain about the possible environmental influences that explain the rise in most adiposity-related indices during period 3. A possible explanation for this fact is the economic recovery Chile experienced in 2003-4, after the Asian Crisis; a greater increase in annual gross national product than in previous years was observed. From 2002 to 2003, this figure (measured in constant values) rose from \$US 90735 million to \$US 94289 million, while in 2004 it increased to \$US 100101 million, i.e. $2 \cdot 3 \%$ more than the previous year $^{(16)}$. The effect of income on obesity prevalence over a wide range of values has been documented by Mbuya and Habicht ${ }^{(17)}$ in their analysis of Brazilian data obtained by Monteiro et al. ${ }^{(18)}$, which showed that there is a significant positive association under extreme poverty, at middle income the effect is non-existent, while at higher income there is a negative relationship. There was a clear, inverted U-shaped curve between log income and obesity prevalence. The finding that there is a wide range of income where no relationship is observed is of relevance and serves to explain the diversity in published work on this topic.

The BMIZ data presented in Tables 3 and 4 suggest small changes between March 2003 and November 2004; in reality, the decline in period 1 was marked, while values rose in the last period. Assessing the overall changes for the 2-year period, by comparing initial and final values, would have clearly missed the substantive differences between the first, second and the third periods. In fact, this comparison showed significant differences between intervention and control groups for boys aged $<8$ years, $8-10$ years and 10-12 years and in the first two categories for girls. In addition, this finding underscores the fact that the effectiveness of the intervention is related mainly to age rather than gender. We conclude that the analysis of results from obesity prevention studies should include age and gender breakdowns and should also assess the effect of any major changes in the context of the intervention. As shown in our study, the weaker intervention in the second year had quite a different impact in the various indicators.

The comparison of effects on BMIZ and on obesity prevalence reveals that the two indices do not necessarily 
behave similarly. We saw a significant drop in obesity prevalence in intervention schools which was sustained over the two years, while BMIZ scores dropped during period 1 and then rose in period 3. This differential response suggest that changes in obese subgroups of the population may not be reflected by changes in mean BMIZ, since there may be a selective response of the obese or a more marked response in the obese subgroup. In fact, in conducting the analysis by periods as illustrated in the figures, we adjusted the observed changes in BMIZ by baseline BMI and found significant effects of age of the children and period of study on these changes. Lack of demonstrable changes in the secondary variables, WC and TSF, could be explained by the greater variability of these measurements or by difference in maturational rates ${ }^{(19)}$ despite the fact that these data were fully standardized within age subcategories. In fact, multivariate analyses of these standardized variables (according to the NHANES III reference) comparing the intervention with the control group showed only a significant difference for TSF in girls ( $P$ for group $\times$ time interaction $=0 \cdot 0008$ ).

The present study demonstrates the importance of sustained efforts to secure a favourable outcome. In addition, it shows the need for greater commitment from educational authorities, ideally before initiating the intervention. The time-related changes in the effects (year 1, recess and year 2) in intervention and control children suggest that the school environment has a clear influence on BMIZ and obesity prevalence. Seasonality may further contribute to the differential effect ${ }^{(20)}$; during the summer, diet and physical activity may be equally protective for both groups, while during the school year the intervention may induce a greater effect.

Most of the activities we implemented had been satisfactorily tested by us during the previous school year. The main reason for our inability to implement the full programme for the two complete school years was that teachers generally regarded them as excessive work (for e.g. CALC program). The nutrition education programme could not be sustained during the second school year since funds were not available for the nutritionist who supported the teachers in their activities with the children; they felt less motivated to comply with all the planned activities. In contrast, other teachers were interested in improving the quality of the physical education (PE) classes; thus we developed an on-site training programme to achieve this goal ${ }^{(21)}$. Unfortunately, we lacked the resources to train all teachers who expressed interest in this type of training (teachers from 1st to 4 th grades). It is important to note that non-PE teachers acknowledged they needed mentoring from a PE teacher to maximize the effective physical activity time spent by students during classes. Parental involvement in general was very insufficient and more so during the second school year.

We suggest that those planning obesity prevention programmes select interventions based on the possibility that these remain in place with minimal demands on teachers' time. For example, additional PE classes, which impose a burden on the teachers, have a very slim chance of sustainability unless teachers are compensated for this work ${ }^{(22)}$.

The most important barriers we encountered in the implementation of our study relate to administrative aspects; for example, additional PE classes. This was quite difficult because the schools use their potential free time to have additional Spanish and maths classes; these subjects are included in the annual evaluation of schools. In addition, teachers reported that they were heavily burdened by the need to implement various programmes during the school year; extra work is not welcome. Our experience shows that unless initiatives are integrated into the school curricula, they are not sustainable and unlikely to produce impact. Other activities, such as parental involvement in supporting healthier diets and more active lives, could be highly effective. Yet unless human resources are put in place, the probability of sustainability is extremely low.

There are several important limitations to the present work that restrict both the intrinsic and extrinsic validity of our study. This study was controlled, but not randomized. As indicated before, this was beyond our control, because the educational authorities chose to test the intervention under the worst conditions: their view was that if it was going to work it should do so in schools where obesity was highly prevalent; the possibility of randomizing children within schools was not considered feasible, as has been demonstrated by others ${ }^{(23,24)}$, and selection of the control school was beyond our scope. We collected available information on potential confounders, addressing mainly the biological variables of the children; however, we did not assess the home environment or the familial susceptibility to obesity and thus some of the differences observed could be attributed to factors other than the intervention. Also the existence of VIDA Chile, a national intervention of which the developed 'Healthy Schools' initiative is part ${ }^{(25)}$, consisting mainly in implementing actions addressing simultaneously three of five risk factors for nutrition-related chronic diseases (healthy diet, physical activity, tobacco control, psychosocial and healthy environment), may have modulated the observed effects. However, it has minimal impact evaluation components that are focused exclusively on process indicators and both Casablanca and Quillota were similarly affected by this programme; thus the differential impact we observed may be attributed to the specific intervention we implemented. The generalizability of these findings has some limitations since the context of the present intervention relies heavily on added human and material resources which may not be available in other settings; moreover, even in our study we were not able to fully sustain the effort for the second year as planned.

Because school-based interventions have the potential for establishing future dietary and physical activity patterns ${ }^{(26)}$, it is important to evaluate those that are most 
feasible to implement and potentially have greater impact. Low-income communities living in countries that have reached the post-transitional stages of the nutrition transition are more susceptible to develop obesity; moreover, these groups have greater difficulty in modifying their physical activity and food intake behaviour. Kumanyika and Grier ${ }^{(27)}$ have shown how various environmental factors can have larger effects on disadvantaged and minority children than on their advantaged peers and thus contribute to disparities in obesity rates. These authors showed, for example, that low-income and minority children watch more television than non-poor children and are potentially exposed to more commercials advertising high-energy, low-nutrient food during an average hour of television programming. A recent review by Doak et $a l^{(28)}$ identified aspects of childhood obesity prevention programmes that were most likely to succeed. The authors considered as effective those programmes where the intervention group showed a statistically significant improvement in comparison to a control group. The basis for their review considered quantitative and qualitative aspects drawn on criteria suggested by Kumanyika et $a l .{ }^{(29)}$. Fifty-six per cent of the interventions included in the review were found to be effective for at least one subgroup. There are no clear-cut factors that differentiate effective from non-effective interventions, although it seems that targeting fewer schools and for shorter periods has been deemed to produce a greater impact on obesity rates. Doak et al.'s analysis serves to reinforce the difficulties involved in implementing effective long-term and wide-scale programmes. Context-specific variables are crucial in defining the outcome of interventions to control childhood obesity; our results illustrate the importance of addressing the intensity of delivery of interventions and assessing the various environmental factors that interact with the intervention in defining the final impact.

\section{Acknowledgements}

The present study was supported by a Chilean company called Tresmontes Lucchetti. There are no conflicts of interest. J.K. carried out the study, collected and analysed the data, and wrote most of the manuscript. B.L. defined the statistical tests, carried out the analyses and participated in its interpretation. R.C. helped in data collection and analyses. F.V. was involved in planning the study and processing the results. R.U. participated in defining the statistical tests, in processing the results and writing this article. We thank all children, teachers and parents for their participation in our study.

\section{References}

1. Kain J, Uauy R, Lera L, Taibo M \& Albala C (2005) Trends in height and BMI of 6-year-old children during the nutrition transition in Chile. Obes Res 13, 2178-2186.
2. Albala C, Vio F, Kain J \& Uauy R (2002) Nutrition transition in Chile: determinants and consequences. Public Health Nutr 5, 123-128.

3. Kain J, Burrows R \& Uauy R (2002) Obesity trends in Chilean children and adolescents: basic determinants. In Obesity in Childhood and Adolescence. Nestlé Nutrition Workshop Series Pediatric Program vol. 49, pp. 45-62 [C Chen and W Dietz, editors]. Philadelphia, PA: Lippincot Williams and Wilkins.

4. Ministerio de Salud de Chile \& Universidad Católica (2006) Primera Encuesta Nacional de Salud 2003. http//epi.minsal. $\mathrm{cl} / \mathrm{epi} / \mathrm{html}$ (accessed November 2006).

5. World Health Organization (1995) Physical Status: The Use and Interpretation of Anthropometry. Report of a WHO Expert Committee. WHO Technical Report Series no. 854. Geneva: WHO.

6. Salinas J \& Vio F (2002) Health promotion in Chile. Rev Chil Nutr 50, 164-173.

7. Kain J, Uauy R, Albala C, Vio F, Cerda R \& Leyton B (2004) School-based obesity prevention in Chilean school children: methodology and evaluation of a controlled study. Int J Obes Relat Metab Disord 28, 483-493.

8. Olivares S, Zacarías I, Andrade M, Kain J, Lera L, Vio F \& Moron C (2005) Nutrition education in Chilean primary schools. Food Nutr Bull 26, Suppl. 2, S179-S185.

9. Olivares S, Moron C, Kain J, Zacarias I, Andrade M, Lera L, Díaz N \& Vio F (2004) A methodological proposal to include nutrition education in primary schools. Experience in Chile. Arch Latinoam Nutr 54, Suppl. 1, S33-S39.

10. Anon. (2001) CALC Program. http://www.cahperd.ca/calc/ index.html (accessed November 2006).

11. National Center for Health Statistics/Centers for Disease Control and Prevention (2000) 2000 CDC Growth charts: United States. http://www.cdc.gov/growthcharts/ (accessed November 2008).

12. Chilean Ministry of Health, Nutrition Unit (2004) Technical norm for the nutritional evaluation of children aged 6 to 18 years of age. Rev Chil Nutr 31, 128-137.

13. Committee of Experts on Sports Research (1988) EUROFIT. Rome: Edigraf, Editoriale Grafica.

14. PaulDickman.com (2007) Using PROC GENMODE for logistic regression (SAS version 6). http://www.pauldickman. com/teaching/sas/genmod_logistic.php (accessed July 2008).

15. McDowell M, Fryar C, Horsch R \& Ogden C (2005) Anthropometric Reference Data for Children and Adults: US Population, 1999-2002. http://www.cdc.gov/nchs/ data/ad/ad361.pdf (accessed October 2007).

16. Chilean Central Bank (2006) Banco Central de Chile. http:// www.bcentral.cl (accessed August 2006).

17. Mbuya MN \& Habicht JP (2005) Letter to the editor: Revisiting the independent effects of income on the risk of obesity. J Nutr 135, 2486.

18. Monteiro C, Conde W \& Popkin B (2001) Independent effects of income and education on the risk of obesity in the Brazilian population. J Nutr 131, S881-S886.

19. Sandhu J, Ben-Shlomo Y, Cole TJ, Holly J \& Davey Smith G (2006) The impact of childhood body mass index on timing of puberty, adult stature and obesity: a follow-up study based on adolescent anthropometry recorded at Christ's Hospital (1936-1964). Int J Obes (Lond) 30, $14-22$.

20. Dietz W \& Gortmaker S (1984) Factors within the physical environment associated with childhood obesity. Am J Clin Nutr 39, 619-624.

21. Kain J, Cerda R, Leyton B \& Uauy R (2005) On-site training to improve the quality of PE classes for 1st and 2nd grade Chilean schoolchildren. Presented at the IV Annual Conference Meeting of the International Society for Behavioral 
Nutrition and Physical Activity, Amsterdam, The Netherlands, 16-18 June.

22. El Mercurio online, emol.com (2006) Se esfuma acuerdo de doblar clases de educación física. http://www.emol.com (accessed August 2006).

23. Robinson T \& Sirard J (2005) Preventing childhood obesity: a solution-oriented research paradigm. Am J Prev Med 28, 194-201.

24. Richter K, Harris K, Paine Andrews A, Faucett S, Smid T, Lankenan B \& Johnsten J (2000) Measuring the health environment for physical activity and nutrition among youth: a review of the literature and applications for community initiatives. Prev Med 31, S98-S111.

25. National Council for Health Promotion (2002) Vida Chile: construyendo un pais más saludable. http://www.paho.org/
Spanish/AD/SDE/HS/EPS_RED_CHI.pdf (accessed February 2007).

26. Lobstein T, Baur L \& Uauy R (2004) Obesity in children and young people: a crisis in public health. Obes Rev 5, Suppl. 1, 60-72.

27. Kumanyika S \& Grier S (2006) Targeting interventions for ethnic minority and low-income populations. Future Child 16, 187-207.

28. Doak C, Visscher TL, Renders C, Renders C \& Seidell J (2006) The prevention of overweight and obesity in children and adolescents: a review of interventions and programmes. Obes Rev 7, 111-136.

29. Kumanyika S, Jeffery R, Morabia A, Ritenbaugh C \& Antipatis V (2002) Obesity prevention: the case for action. Int J Obes Relat Metab Disord 26, 425-436. 